\title{
Diabetes care: who are the experts?
}

\author{
Tim Hares, John Spencer, Morris Gallagher, Colin Bradshaw, Ian Webb
}

\begin{abstract}
Objectives - To identify issues that patients and professionals consider important in diabetes care and differences in their priorities for care and to determine patients' and professionals' judgements of the relative importance of their chosen priorities.
\end{abstract}

Design - Structured group interviews using the nominal group technique.

Setting - Five district health authorities on Tyneside.

Subjects - Five nominal groups: expert (seven), non-expert (seven) health care professionals; insulin dependent (four), non-insulin dependent patients (eight); and carers of diabetic patients (eight).

Main measures - Items important in diabetes care to each nominal group (themes of care), ranked into a series of "top 10" items for each group, and allocated a score according to relative importance to individual members; scores were standardised by individual weighting and group weighting for comparison within and between groups.

Results - Patients and professionals agreed that information given to patients, interaction between professionals and patients, patient autonomy, and access were important for good diabetes care, but the importance assigned to each differed. Thus the professionals emphasised empathy and aspects of good communication and patients the desire to know enough to live a "normal" life. Differences were also found within the patient groups; these related to changes in patients' needs at specific points in the development of their illness and in their orientations to care.

Conclusion - Patients differ from professionals in their orientation to diabetes care, and they can, and should, be involved in setting priorities for care. Since these priorities are dynamic further work is needed to explore the nature of patient satisfaction with diabetes care. (Quality in Health Care 1992;1:219-224)

\section{Introduction}

Patients, professionals, and politicians are all concerned about quality of care. The 1989 white paper Working for Patients outlined the government's intention of making health services responsive to consumer demand. ${ }^{1}$ This intention is reflected in the patient's charter, which emphasises that the NHS belongs to the public and that patients will be involved in assessing care. ${ }^{2}$ In the context of diabetes, patients' concern over quality of care is reflected in publications such as the British Diabetic Association's leaflet What Diabetic Care to Expect, which details the standard of care that a patient should expect from their medical carers. ${ }^{3}$

Many think that patients are better placed than providers to judge such measures as quality of responsiveness, accessibility of care, the environment in which care is provided, and the attitudes of providers to their patients. ${ }^{45}$ Despite well documented theoretical problems ${ }^{6-9}$ measures of patient satisfaction are increasingly being used as indicators of quality of care.

Diabetes mellitus is a chronic condition, requiring lifelong management and care from multidisciplinary professional teams. The aim of this study was to examine the issues that patients, carers, and a range of professionals felt were important in providing diabetes care and to explore any differences in priorities of care either within or between these different groups. Nominal Group Technique was chosen as it is a versatile structured group interview process that yields data on the types of differences of opinion that exist between participants and on their underlying logic and relative importance. ${ }^{10}$ The method allows qualitative differences to be quantified and their meaning to be determined from a single data set.

\section{Subjects and methods}

COMPOSITION OF NOMINAL GROUPS

The groups were chosen to reflect the full range of professionals and non-professionals involved in the care process. Table I shows the membership of each group.

Health care professional groups - Two professional nominal groups were assembled: "experts" and "non-experts." The experts

\section{Table 1 Membership of nominal groups}

\begin{tabular}{ll}
\hline Group & No \\
\hline Health care professional: & \\
Expert & 7 \\
General practitioner & 2 \\
Hospital consultant & 1 \\
Dietitian & 1 \\
Practice nurse & 1 \\
Specialist nurse & 1 \\
Chiropodist & 1 \\
Non-expert & 7 \\
General practitioner & 2 \\
Chiropodist & 2 \\
Practice nurse & 1 \\
Dietitian & 1 \\
Community Health Council officer & 4 \\
Insulin dependent diabetic patients & 8 \\
Non-insulin dependent diabetic patients & 8 \\
Carers & 3 \\
Of patients aged <12 years & 2 \\
Of patients aged 15-21 years & 3 \\
Of patients aged >65 years &
\end{tabular}


were known to be involved in development of diabetes care in the region, and the nonexperts were mainly involved in primary care and were not known to be active in development of diabetes care, yet were willing to participate in group discussion. The professionals were recruited to cover the range of professionals involved in patient care on Tyneside, including dietitians, general practitioners, specialist nurses, chiropodists, and consultants. The professional nominal groups were structured by expertise rather than specialty to allow differences between specialties, should they exist, to be articulated during discussion.

Non-professional groups comprised three groups: insulin dependent diabetic patients, non-insulin dependent diabetic patients, and carers of diabetic patients from South Tyneside. As there is no district register of diabetic patients in South Tyneside potential participants were randomly selected from patient lists by general practitioners and invited to attend. We sent letters to 50 patients and carers detailing the aims of the project and the method to be used and offering to cover travel costs; we received $22(44 \%)$ replies. The respondents were a self selected sample, yet we had asked those who were diabetic patients to supply details of their age, sex, treatment type, length of diagnosis, and complications. We were not attempting to make inferential statements concerning our data, rather we wished to explore some of the issues that were important to patients and carers. We invited 20 patients and carers all of whom attended.

\section{NOMINAL GROUP TECHNIQUE}

Nominal group technique (NGT) is a form of group discussion that allows differences in opinions to be measured and gives participants the chance to explain their contributions while restricting interaction between them. The group is "nominal" as during the initial stages the participants are not allowed to communicate - the group is thus a group in name only, a nominal group.

Detailed guidance on the NGT is available elsewhere. ${ }^{11} 12$ Briefly, between four and eight participants take part in a discussion which closely follows a set format (box). Participants are asked silently to write responses to a question for 10-15 minutes. They then read out their responses in turn, which a group

\section{Stages in running a nominal group}

Generating ideas

(1) Silent generation of ideas in response to a question

(2) Listing ideas from each participant in turn

(3) Discussing ideas and grouping into related areas

Scoring technique

(4) Voting on importance of issues

(5) Discussing results of the "top 10 " most important issues

(6) Voting again and "scoring" of issues facilitator notes on a flipchart. At this stage participants are not allowed to talk freely to each other but are encouraged to "piggy back" ideas in response to the ideas of others when their turn is due. This continues for several rounds until there are no new ideas. Then follows a discussion section in which the participants are free to elaborate, defend, and criticise ideas, after which they vote on the importance of the ideas and assign a rank order. A list of the "top 10" ideas is produced, and the result is discussed. A second vote is taken, with participants awarding points to reflect an item's relative importance. Each group session lasted from one and a half to two hours. The following explicit question was set before the group session started: "What things are important in making people satisfied with diabetic care?"

A total of six nominal groups ran between October and December 1991, including a pilot group. Each session was tape recorded and transcribed for analysis. The pilot group proved the worth of a nominal group approach in generating discussion on themes and priorities of care.

\section{SCORING SYSTEM}

The scoring system was that described by Delbecq et al. ${ }^{10}$ Scoring occurred in two stages. After the items had been generated (stages 1-3, box) the importance of each was ranked by each participant, who gave 10 points to the most important item, 9 to the second most important, down to 1 . Points from all participants in a group were added together to find the "top 10" most popular items for each nominal group. Secondly, each participant was asked to give the issues in the final top 10 a relative score. Each participant awarded 100 points to the item he or she considered to be the most important, with any scores between 99 and zero being given to each of the others in the "top 10". The scores had to reflect the rank order, but within this limitation participants were free to vary the scores.

To allow comparisons across different participants we standardised these scores ${ }^{13}$ by applying a standardised weighting for each item obtained from the formula:

\section{Score for the item/sum of all scores given by the participant}

The result shows the relative worth of an item compared with all others in the top 10 . Direct comparison of the raw scores would not reflect the relative worth assigned to the items by participants. These standardised weightings allowed comparisons at two levels of analysis: between different members of the same group and within the relative scores of individual members. As the item sets differ for each group, formal statistical analyses cannot be carried out to compare different groups. An analysis of variance (with SPSS PC+) was used to look for differences in the weightings given to the items by "clinical" experts and "facilitative" experts in the expert professional nominal group. 
Table 2 Themes generated inductively from items of importance in diabetes care

\begin{tabular}{|c|c|}
\hline Theme & Items \\
\hline $\begin{array}{l}\text { Access to } \\
\text { care }\end{array}$ & $\begin{array}{l}\text { Short waits at hospital } \\
\text { Easy travel to care } \\
\text { Able to see doctor when you want }\end{array}$ \\
\hline $\begin{array}{l}\text { Patient } \\
\text { autonomy }\end{array}$ & $\begin{array}{l}\text { Able to discuss results and suggest changes } \\
\text { Relative autonomy in own care }\end{array}$ \\
\hline $\begin{array}{l}\text { Patient } \\
\text { information }\end{array}$ & $\begin{array}{l}\text { Explains diabetes and its complications } \\
\text { Understandable } \\
\text { Consistent }\end{array}$ \\
\hline $\begin{array}{l}\text { Patient- } \\
\text { professional } \\
\text { interaction }\end{array}$ & $\begin{array}{l}\text { Feel able to talk to doctor } \\
\text { Feel doctor listens to you } \\
\text { Professionals to talk to each other and to you }\end{array}$ \\
\hline $\begin{array}{l}\text { Social } \\
\text { dimensions }\end{array}$ & Information you can afford to act on \\
\hline Support & $\begin{array}{l}\text { Home visits by diabetes nurse } \\
\text { Someone to talk to }\end{array}$ \\
\hline Treatment & $\begin{array}{l}\text { Regular checks at a diabetes clinic } \\
\text { Having professionals involved at the clinic }\end{array}$ \\
\hline
\end{tabular}

\section{Results}

Analyses were carried out on the full lists of ideas generated in response to the question, the first and second round votes for the "top 10 " in each group, and the taped discussion sections.

\section{THEMES OF CARE}

All of the items generated in response to the question "What things are important in making people satisfied with diabetes care?" were classified into categories of themes, which were themselves generated inductively from the items, to show the range of issues that were considered important. Table 2 lists the themes and examples of the items they contain. There was some potential overlap between categories, specifically between information and autonomy. The statement "Enough understanding of diabetes to live as free a life as possible" was categorised as autonomy, as that was the underlying idea. Table 3 summarises the themes raised by the group members. There were differences between the patient groups in terms of the complexity of the categories and, by implication, their importance. For example, the insulin dependent patient group generated five items concerning autonomy in care (including promoting relative autonomy in care, being given choice in care, and being treated as an individual with specific needs and wishes) whereas the non-insulin dependent patient group generated only one. The following seven themes emerged out of the items.

Access to care - The professional groups considered convenience of the site of care and timing of appointments, short waiting times, and emergency and repeat prescriptions as important issues. Patients shared these concerns and also raised the issue of being seen when they wanted information or general help.

Patient autonomy - All patient groups wanted to be seen as "people" rather than "diabetic patients". Both insulin dependent diabetic patients and carers made links between autonomy, knowledge, and information. Both wanted to increase their freedom through holding information, and the patients
Table 3 No of items of importance in diabetes care generated by each group

\begin{tabular}{lccccc}
\hline & \multicolumn{5}{c}{ Group } \\
\cline { 2 - 6 } Theme & Carers & $\begin{array}{c}\text { Insulin } \\
\text { dependent } \\
\text { diabetic } \\
\text { patients }\end{array}$ & $\begin{array}{c}\text { Non-insulin } \\
\text { dependent } \\
\text { diabetic } \\
\text { patients }\end{array}$ & Experts & $\begin{array}{c}\text { Non- } \\
\text { experts }\end{array}$ \\
\hline $\begin{array}{l}\text { Acess to } \\
\text { care }\end{array}$ & 3 & 3 & 5 & 4 & 5 \\
$\begin{array}{l}\text { Patient } \\
\text { autonomy }\end{array}$ & 5 & 5 & 1 & 4 & 5 \\
$\begin{array}{c}\text { Patient } \\
\text { information }\end{array}$ & 4 & 4 & 8 & 4 & 4 \\
$\begin{array}{c}\text { Patient- } \\
\text { professional }\end{array}$ & 0 & 2 & 5 & 8 & 4 \\
interaction & 1 & 0 & 1 & 0 & 1 \\
$\begin{array}{c}\text { Social } \\
\text { dimensions }\end{array}$ & 3 & 2 & 1 & 1 & 1 \\
$\begin{array}{l}\text { Support } \\
\text { Treatment }\end{array}$ & 4 & 5 & 0 & 5 & 9 \\
\hline Total & 20 & 21 & 21 & 26 & 29 \\
\hline
\end{tabular}

also wanted to be given a choice in their care. Both professional groups were aware of these issues, yet emphasised empathy more than autonomy.

Patient information - The professional groups thought that written information on lifestyle and diet should be understandable, consistent, and freely available. Patients echoed these concerns, but felt the nature and quality of oral information was also important.

Patient-professional interaction - Patients emphasised the importance of communication with, and the honesty of, professionals and were also concerned about coordination of care between primary and secondary care professionals. Experts generated more items on this than any other theme, showing sensitivity to the interpersonal aspects of the consultation process.

Social dimensions - The non-insulin dependent diabetic patient group raised the issue of appropriate advice, as advice on foods was of little use if patients could not afford the diet. The carers also wanted nutritional advice to appear on all foodstuffs. Only the "expert" group mentioned the economic consequences of diabetes care in terms of NHS resources.

Support - All groups agreed that contact with others in the same situation was useful, particularly for carers. Carers wanted support from professional staff as well as from other carers, who could teach by example and offer informal advice.

Treatment - Non-insulin dependent diabetic patients did not mention their treatment explicitly, whereas insulin dependent diabetic patients and their carers thought that attendance at a clinic staffed with professionals and a degree of continuity of care was important. Patients did not mention that their treatments should make them feel well or be as painless as possible, an issue raised by both professional groups. Non-expert professionals generated almost twice as many items on this theme as any other, showing concentration on a "medical" model of care.

NOMINAL GROUP RANKINGS

The second round group votes for the top 10 
items show differences in importance between the nominal groups, which are summarised in tables 4 to 8 ). These tables show the rank orders and standardised group weightings, obtained from the following formula:

standardised group weighting =sum of the individual weights of each member of the group/number of members in the group

The ranking and weighting combined shows how much more important the higher ranked items are. The weightings are direct proportions; therefore an item with a weight of 0.5 is half as important for the group as an item with a weight of 1.0 .

The professional groups seemed most concerned with empathy and continuity of care (tables 4,5 ) whereas the patient and carer groups were most concerned with issues of information, autonomy, and support (tables 6-8).

Professional groups - The professionals emphasised a continuing relationship with empathic, responsive, and receptive professionals. Positive feedback on treatment compliance was also highly rated and was considered more important than access to consistent advice. There was considerable agreement between the rankings of the two groups (tables 4,5 ).

Non-insulin dependent diabetic patients placed much more emphasis on the explanation of the condition and the availability of clear, consistent information, particularly at diagnosis, a time of considerable stress. Those without prior experience of diabetes felt particularly vulnerable at this time. For those with complications or other conditions advice on those symptoms due to diabetes was considered very useful. Issues of access and waiting times were not a high priority (table 6).

Insulin dependent diabetic patients placed more emphasis on treatment than other nonprofessional groups (table 7). This is not

Table 4 Rank order and group weighting of top 10 items by expert professionals

\begin{tabular}{llc}
\hline Rank & \multicolumn{1}{c}{ Item } & Weight \\
\hline 1 & Continuity of relationship & 1.15 \\
2 & Advice easy/practical to implement & 1.14 \\
3 & Listening/caring professional & 1.07 \\
4 & Feeling enough time has been spent & 1.06 \\
5 & Positive feedback and encouragement on & 1.03 \\
& achievements patient has agreed to & \\
6 & Confidence in professional ability/skills & 1.02 \\
7 & Easy access to advice & 0.96 \\
8 & Efficient appointment systems & 0.90 \\
9 & Consistency of advice from each team member & 0.86 \\
10 & Joint decision making & 0.80 \\
\hline
\end{tabular}

Table 5 Rank order and group weighting of top 10 items by non-expert professionals

\begin{tabular}{llc}
\hline Rank & \multicolumn{1}{c}{ Item } & Weight \\
\hline 1 & Patient treated as a "person" & 1.27 \\
2 & Well run clinic & 1.20 \\
3 & Continuity of care & 1.14 \\
4 & Understanding professionals & 1.04 \\
5 & Welcoming staff/professionals & 1.02 \\
6 & Good communication between professionals & 0.96 \\
7 & Ease of access to appointment & 0.89 \\
8 & Good information (accessible, repeated) & 0.88 \\
9 & Minimal upset to patient's life & 0.87 \\
10 & Awareness of a standard of care & 0.75 \\
\hline
\end{tabular}

Table 6 Rank order and group weighting of top 10 items by non-insulin dependent patients

\begin{tabular}{llc}
\hline Rank & \multicolumn{1}{c}{ Item } & Weight \\
\hline 1 & $\begin{array}{l}\text { Explaining diabetes and its complications on } \\
\text { diagnosis }\end{array}$ & 1.02 \\
2 & Complete and clear information & 0.94 \\
3 & Consistent information & 0.92 \\
4 & Being able to talk to doctor & 0.80 \\
5 & Confidence in doctor to give advice & 0.68 \\
6 & Knowing what symptoms relate to diabetes & 0.67 \\
7 & Able to see doctor when you want to & 0.60 \\
8 & Professionals to talk to each other and keep & 0.47 \\
9 & you informed & 0.46 \\
10 & Good advice on diet and treatment & 0.44 \\
\hline
\end{tabular}

Table 7 Rank order and sample weighting of top 10 items by insulin dependent patients

\begin{tabular}{llc}
\hline Rank & \multicolumn{1}{c}{ Item } & Weight \\
\hline 1 & Treating each patient as an individual & 1.30 \\
2 & Attending a good clinic & 1.22 \\
3 & Having professionals involved in care & 1.09 \\
4 & Liaison between general practitioner and & 1.07 \\
& consultant & 1.06 \\
5 & Honesty by doctors & 1.05 \\
6 & Given a choice in care & 0.95 \\
7 & Information to families & 0.80 \\
8 & Regular checks on blood glucose concentration & \\
& and weight & 0.78 \\
9 & Easy access (physical) & 0.72 \\
\hline 0 & Seeing the same doctor & \\
\hline
\end{tabular}

surprising, given the emphasis on blood glucose control and the need to balance food intake with insulin. Attendance at a clinic staffed with the range of professionals necessary to monitor control and spot possible complications was considered very important. Choice of care was sixth in the list but the source of much disagreement within the group. This was of prime importance to one member, who substantially disagreed with the group scores.

Carers were most concerned about access to professional help and made links between treatment, information, and increased patient autonomy. Information on diet and treatment was requested in order to make the patient's life as uninterrupted as possible (table 8).

DIFFERENCES WITHIN GROUPS

Differences were apparent in the second round scores of individuals within the expert professional group and individuals within the insulin dependent diabetic patient group.

Expert professionals group - Large variations were found in the votes during the first round in the ranks given to items 2 ("advice easy/ practical to implement"), 7 ("easy access of advice"), and 3 ("listening/caring professional"). After the second round of scoring and weighting the scores were subdivided into those for "clinicians" (general practitioner,

Table 8 Rank order and group weighting of top 10 items by carers

\begin{tabular}{llc}
\hline Rank & \multicolumn{1}{c}{ Item } & Weight \\
\hline 1 & Regular checks at a diabetic clinic & 1.28 \\
2 & Information on first diagnosis & 1.05 \\
3 & Seeing the same person & 1.04 \\
4 & Thorough knowledge of diet/treatment to & 1.03 \\
& increase freedom & 1.02 \\
5 & Access to new information & 0.99 \\
6 & Consistent information & 0.98 \\
7 & General practitioner to have a clinic & 0.96 \\
8 & Confidence in staff abilities & 0.94 \\
9 & Support from other parents/schools & 0.75 \\
10 & More home visits by diabetes nurses & \\
\hline
\end{tabular}


Table 9 Variation between two group members in standardised weighted scores for top 10 items by insulin dependent patients

\begin{tabular}{lcc}
\hline Item & Patient $A$ & Patient B \\
\hline Attending a good clinic & 0.13 & 0.11 \\
Treating each patient as an individual & 0.12 & 0.19 \\
Having professionals involved in care & 0.13 & 0.09 \\
Honesty by doctors & 0.09 & 0.11 \\
Information to families & 0.08 & 0.10 \\
Regular checks on blood glucose & 0.11 & 0.02 \\
concentration/weight & 0.11 & 0.02 \\
Easy access (physical) & 0.09 & 0.17 \\
Liaison between general practitioner & & \\
and consultant at hospital & 0.07 & 0.02 \\
Seeing the same doctor & 0.07 & 0.19 \\
Given a choice in care & & \\
\hline
\end{tabular}

consultant, chiropodist) and those for "facilitators" (specialist nurse, dietitian, facilitator) for further analysis. In practice, the chiropodist was difficult to place into either category, given the specific nature of the role of the specialist nurse and dietitians. These professional groups act very much as patient advocates and points of contact for general information about diabetes through non-clinic contact and involvement in self help initiatives. Contact with chiropodists is limited to clinical settings either at the hospital or at some of the general practitioner diabetes clinics. It was on this basis that the chiropodist was assigned to the clinician group.

An analysis of variance to test the hypothesis that clinicians and facilitators do not differ on the relative importance assigned to the items showed no significant professional group effect even when the chiropodist scores were assigned to the facilitator category. The large variations in rankings were not reflected in the more sensitive measure of standardised scores: the differences were caused by the lack of precision in the earlier measures.

Insulin dependent diabetic patients - Within this group there were large variations in the rankings of some of the items in the top 10 and an even greater variation after scoring and weighting. One participant disagreed substantially with the others in the relative importance of autonomy. This is best shown by the standardised weights given for the top 10 by two participants (table 9). Patient A gave importance to issues surrounding good access to professional care in a clinic setting, with close monitoring of blood glucose concentration and weight. Patient $A$ also wanted to be "treated as an individual" by the professionals. Patient B wanted to attend a good clinic but was very concerned about honesty and the degree of choice in treatment regimens. Continuity of care, access, and regular monitoring of blood glucose concentration by professionals were all given very low scores. Being given a choice in care was almost 10 times as important as continuity of care for this patient.

\section{Discussion}

Variants of the NGT have been used in health research in setting priority areas, ${ }^{14-17}$ forecasting the effects of policy change, ${ }^{18} 19$ and problem solving or decision making. ${ }^{20}$ The technique has been recommended as a tool for exploratory research into health problems. However, the simple scoring methods suggested in the original work ${ }^{10}$ may hide or exaggerate variations in the perceived importance of the items. Care must be taken when using the method with groups whose priorities differ, if a "false consensus" result is to be avoided. If standardised weightings are calculated the scale of the disagreements within and across groups becomes clear.

The non-expert professionals voted with a large degree of agreement. These items do not seem to be "disease specific" but rather cover aspects of the balance of power between professionals and patients, and the nature of their relationship. The emphasis on patientprofessional communication and continuity of relationship by the professional groups could be a reflection of the role of "expert" that these professionals occupy: they are concerned to treat patients as human, yet occupy positions of status. They apply their specialist knowledge while being as considerate as possible towards their patients. They did attempt to treat patients as individuals but saw this as an issue of communication rather than one of patient empowerment.

There were disagreements on priorities within the patient groups. There is evidence that the patients weighted the items on the basis of their beliefs about the importance of autonomy in health care and their particular concerns at different stages of their "career" of illness. The first was highlighted by those differences found in the insulin dependent patient group. It hints at a situation in which some patients require professionals to "look after them" and others want to be enabled to "look after themselves". The second is evident from the discussions of the items, in which patients tied their concerns to specific incidents, typically onset of disease, change of treatment, and suspected complications. An example of the way in which one patient emphasised information will make this clear. "...you see when I went into hospital he never told me nothing (sic). All he said was, 'Oh yes, you're X's patient. You'll get some tests,' you know? Really it wasn't very much information I needed, because I'd nursed my husband until he died of diabetes, but you're just sat there, and I really felt, well, I'm a zombie sitting here. You should be telling me, you know?"

Patients have differing understandings of their condition and have dynamic concerns rooted in their differing experiences of the condition, which they bring with them when making judgements on the importance of elements of care. Measures of satisfaction in patients with chronic illness need to be sensitive to the "disease career" of patients and the changes they undergo. ${ }^{21}$ Professionals are wise to treat patients as individuals, and this means more than simple communication skills.

This study showed that diabetic patients can and do set priorities for their care. The results are not generalisable to a whole population but give clues to those areas that may be important in satisfaction with diabetes care. Although 
NGT has been used extensively with "experts," they have tended to be expert providers. We have shown that patients with diabetes are also able to provide information on their priorities. Their involvement in policy making is both possible and desirable. This is particularly important when priorities differ. In this study the importance of information about the condition and treatments available was underestimated by the professionals in these groups.

If measures of satisfaction are to be developed they must be sensitive to the contexts and concerns of patients, ${ }^{22}$ particularly those with chronic illness. Although "information" was rated most highly by non-insulin dependent diabetic patients, its importance was highlighted with reference to episodes of care at specific points in the development of the disease. Priorities are not static - rather they are dynamically related to the experience of patients as they come to terms with, and live with, their disease. Policy change requires identification of which patients are dissatisfied and why, rather than ascertaining simple distributions of satisfaction. The focus is on the individual needs of different patients. A blanket response to calls for "more information" would not necessarily address the specific questions that gave rise to the concern; more advice on diet does not help patients to understand why they will have to start to inject insulin even though they perceive their control of blood glucose concentration to be good with tablets and regulation of their diet. Patients' evaluations of care will become increasingly positive as services become more responsive. In order to respond professionals need to know the processes that give rise to concerns that may not be addressed by a routine review.

Our results clearly show the dynamic nature of patients' priorities for care and emphasise the need for health care to be responsive to the constantly shifting needs of different individual patients. There is scope for further investigation of the nature of these shifting priorities in diabetic patients. Our conclusions are currently being developed in unstructured individual interviews with patients to explore how expressed concerns relate to patient contexts. They will also be used in developing a questionnaire for a random sample of patients in South Tyneside. On this basis we hope to construct a valid and reliable tool for the audit of patient satisfaction with diabetes care.

We acknowledge the financial assistance of the Royal College of General Practitioners' scientific foundation board and of the Department of Health.

1 Secretaries of State of Health, Wales, Northern Ireland, and Scotland. Working for paticnts. Iondon: HMSO, 1989 . (Cmnd 555 .)

2 Department of Health. The paticnt's charter: London: HMSO, 1991

3 British Diabetic Association. What diabetic care to expect. London: BDA, 1990

4 Irvine D. Managing for quality in general practice. London: King's Fund Centre, 1990

5 Hughes J, Humphrey C. Medical audit in general practice London: King's Fund Centre, 1990.

6 Locker D, Dunt D. Theoretical and methodological issues in sociological studies of consumer satisfaction with medical care. Soc Si Med 1978;12:283-92.

Calnan M. Towards a conceptual framework of lay evaluation of health care. Soc Sci Med 1988;27:927-33.

8 Fitzpatrick R, Hopkins A. Problems in the conceptual framework of patient satisfaction research: an empirical framework of patient satisfaction research: an empirical
exploration. Sociology of Health and Illness exploration. So $1983 ; 5: 297-311$.

9 Baker R. Patient satisfaction: how to gauge it. Medical Monitor 1989 Aug 18:4-5.

0 Delbecq AL, Van de Ven AH, Gustafson D. Group techniques for programme planning: a guide to nominal group and Delphi processes. Glenview, Illinois: Scott, Foresman \& Company, 1975.

11 Van de Ven AH, Delbecq AL. The nominal group as a research instrument for exploratory health studies. $A m \mathcal{7}$ Public Health 1972;62:337-42.

12 Horton JN. Nominal group technique: a method of decision making by committees. Anaesthesia $1980 ; 35: 811-4$

13 Clark A, Friedman MJ. The relative importance of treatment outcomes: a Delphi group weighting in mental health. Eraluation Review 1982;6:79-93.

14 Bond S, Bond J. A Delphi survey of clinical nursing research priorities. F Adv Nurs 1982;7:565-75.

15 Charlton JRH, Patrick DL, Matthews G, West PA Spending priorities in Kent: a Delphi study. 7 Eidemiol Community Hialth 1981;35:288-92.

16 Whittle JG, Grant AA, Saril DW, Worthington HV. The Delphi technique: its use in dental health services research assessed in a study to improve care for elderly mentally ill patients. Community Dent Health mentally ill $1987 ; 1: 205-14$

17 Bostwick DH, Foss G. Obtaining consumer input: two strategies for identifying and ranking the problems of mentally retarded young adults. Education and Training of the Mentally Retarded 1981;207-212.

18 White E. A Delphi study on psychiatric nursing. Nursing Times 1991;87:48-9.

19 Gabbay J, Francis L. How much day surgery? Delphi predictions. BMF 1988;297:1249-52

20 Shaw-Phillips M, McGowan BC, Williams RB. Solving problems through staff participation in focus groups. $A m$ f Hosp Pharm 1986;43:1214-7.

21 Bury M. The sociology of chronic illness: a review of research and prospects. Sociology of Health and Illness research and prosf

22 Fitzpatrick R. L ay concepts of illness. In: Fitzpatrick R, Huxton J, Newman S, Scambler G, Thompson J, eds. Huxton J, Newman S, Scambler G, Thompson J, eds.
The experienci of Illnes. London: Tavistock, The experien
1984:11-32. 